\title{
A Step-by-Step Procedure to Perform Preliminary Designs of Salient-Pole Synchronous Generators
}

\author{
Thiago de Paula Machado Bazzo ${ }^{1, * \mathbb{C}}$, Vinicius de Oliveira Moura ${ }^{1}$ and Renato Carlson ${ }^{2}$ (D) \\ 1 Graduate Program on Energy Systems (PPGSE), Universidade Tecnológica Federal do Paraná (UTFPR), \\ Curitiba 80230-901, Brazil; viniciusmoura@alunos.utfpr.edu.br \\ 2 Electrical Engineering Department, Universidade Federal de Santa Catarina (UFSC), \\ Florianópolis 88040-900, Brazil; rencarlson@icloud.com \\ * Correspondence: thiagobazzo@utfpr.edu.br; Tel.: +55-41-992790089
}

Citation: Bazzo, T.d.P.M.; Moura, V.d.O.; Carlson, R. A Step-by-Step Procedure to Perform Preliminary Designs of Salient-Pole Synchronous Generators. Energies 2021, 14, 4989. https://doi.org/10.3390/en14164989

Academic Editor: Oscar Barambones

Received: 30 June 2021

Accepted: 11 August 2021

Published: 14 August 2021

Publisher's Note: MDPI stays neutral with regard to jurisdictional claims in published maps and institutional affiliations.

Copyright: (c) 2021 by the authors. Licensee MDPI, Basel, Switzerland. This article is an open access article distributed under the terms and conditions of the Creative Commons Attribution (CC BY) license (https:// creativecommons.org/licenses/by/ $4.0 /)$.

\begin{abstract}
This paper presents a straightforward step-by-step procedure to design salient-pole synchronous generators, starting with its main specifications and finishing with all necessary data to put it on production. As most of the electricity is generated by synchronous generators, the design of these machines remains an interesting subject, but, although it is important, it is difficult to find a complete step-by-step procedure in the literature. The proposed procedure can be followed by an electrical engineer or student and, distinctively from most papers and books, all steps are presented. Such a procedure is based on analytic calculations, eventually relying on finite element simulation to verify if everything is all right and to adjust some design parameters. All calculations have been chosen to keep the design as simple as possible; otherwise, it would not be possible to present all steps and procedures. Therefore, it can be used for beginners in the art of design-synchronous generators, applied to obtain an initial design, or be adopted by any electrical engineering course, not only aiming to be an introductory electrical machine design course but mainly to enhance the students' comprehension of synchronous machines. The results have been compared with finite element simulation, presenting very small differences.
\end{abstract}

Keywords: design methodology; electric machines; step-by-step design; synchronous generators

\section{Introduction}

Synchronous generators are the most important equipment in electrical energy production. Despise some applications, such as photovoltaic and micro energy harvesting, synchronous generators are the components responsible for converting the mechanical energy, provided by the primary mover, into electricity.

Although synchronous generators design is already well established in the literature, there is still space for innovation in that field and a continuous necessity for specialists to deal with the ever-growing demand for electrical energy. Furthermore, recent energy sources, such as small wind turbines and tidal power, require novel machines optimized to gather as much energy as possible from the natural resource.

There are several bibliography materials addressing electrical machines design [1-4]. These materials provide an excellent understanding of the main types of electrical machines and explain the conceptual issues regarding electrical machine design, e.g., modeling leakage flux and taking into account the winding factor. Additionally, there are quite a lot of papers about this subject [5-12]. Nevertheless, most of these papers are focused on analysis, presenting the results and the advantages of a designed machine. The remaining few concerning the design process [13-15] do not address wound-rotor salient-pole synchronous generators. Moreover, it is extremely rare to find a paper presenting a complete design procedure. Generally, the conception of the design is presented, but it is difficult to use the paper to design a machine on its own. 
This paper presents a straightforward step-by-step procedure to design salient-pole (wound-rotor) synchronous generators. The proposed procedure does not lead to a competitive industrial design neither brings technical innovation. Instead, it presents a simplified procedure that takes into account the fundamental requirements of the generator but neglects some features, such as the damper winding design and dynamical requirements. Nevertheless, these simplifications made it possible to present the entire process in the paper, including all steps necessary to design a synchronous generator, which makes the results easy to reproduce.

The presented procedure, due to its ease of replication, is intended to contribute to several applications. Beginners in designing electric machines may use it to perform their first designs and gain experience. On the other hand, experienced designers could improve the proposed method, including complexity, to achieve a more realistic and competitive machine. Moreover, specialists in other areas, such as power electronics, power system stability, or optimization, generally have some trouble finding all necessary data of electrical machines to use in their research and could achieve all generator parameters from their own design (a method for transient parameter determination to model the generator by an equivalent electrical circuit is presented by [16]). Finally, it can be used as an undergraduate course in electrical engineering to introduce electric machine design and deepen the students' knowledge about synchronous generators and their applications.

\section{Materials and Methods}

\subsection{Generator Topology}

The proposed methodology is suitable to design salient-pole wound-rotor (inner rotor) synchronous generators. The topology of such a machine is presented in Figure 1, where it can be noticed that the air-gap between pole shoes and the internal diameter of stator is constant. This assumption has been considered to keep the design as simple as possible. However, the design procedure can be easily improved to consider a variable air-gap if desired.

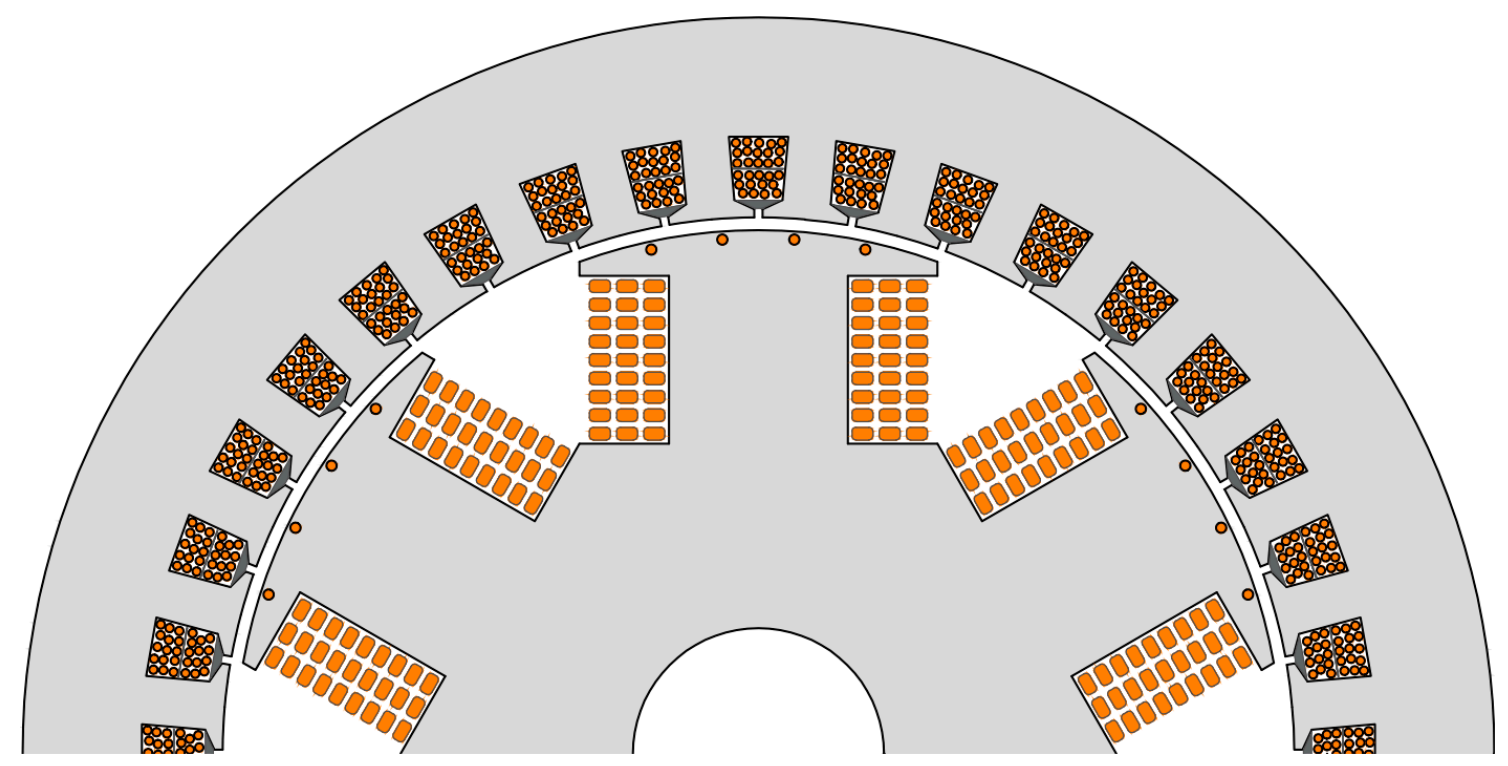

Figure 1. Cross-section representing the topology of the synchronous generator to be designed.

The design procedure allows either single-layer or double-layer armature winding. Although the design equations regard the bottom of the slot as straight-shaped (trapezoidal slots), a rounded bottom (dashed lines in Figure 2) could be easily implemented by changing (24) to calculate the correct slot surface that would be slightly reduced. 


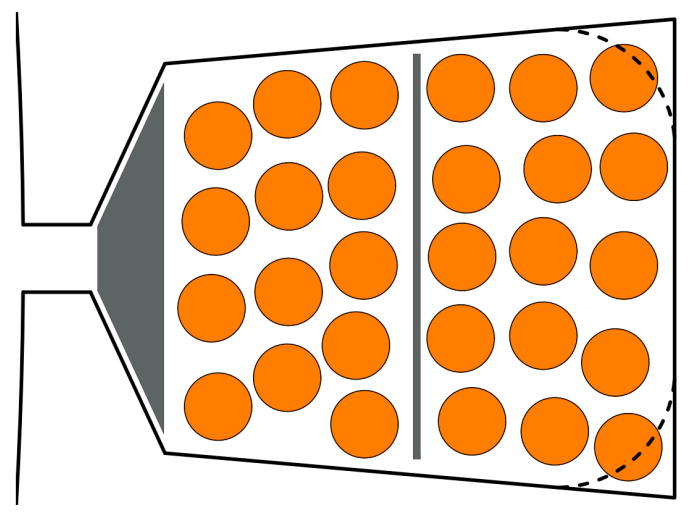

Figure 2. Detail of the slot.

It has been chosen to use 36 slots and double-layer lap windings, which results in 36 coils, meaning 2 coils per pole per phase. The winding diagram is shown in Figure 3.

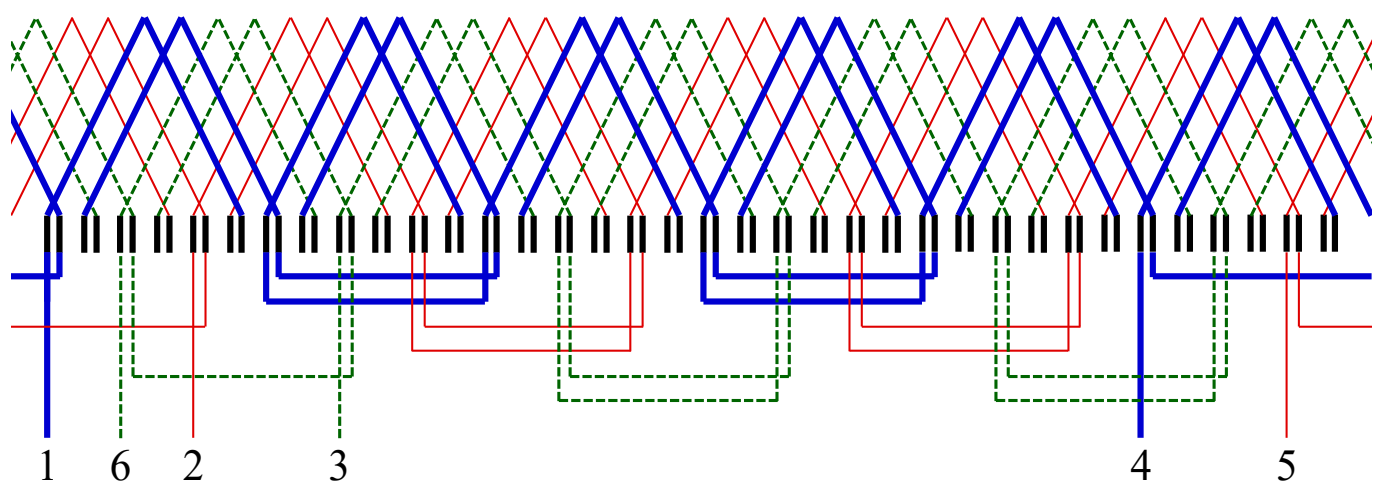

Figure 3. Winding diagram.

The calculations presented in Section 2.3 and the simulations presented in Section 3 assume the generator terminals are $Y$ connected. Then, terminals 4,5 , and 6 of Figure 3 are shortened, and terminals 1, 2, and 3 correspond to phases A, B, and C, respectively.

\subsection{General Design Flow}

The design begins with the design specifications, such as machine type, type of construction, number of phases, rated power, rated rotational speed, rated frequency, power factor, and rated voltage [1]. The present procedure regards 3-phase salient-pole wound-rotor synchronous generators, for which specifications are presented in Section 3.

The next stage is the initial sizing of the synchronous generator to define its main dimensions, mainly the rotor external diameter. Such a value can be obtained from the admissible tangential stress in the air-gap, which is calculated from tolerated values of the linear current density and the flux density in air-gap. These allowable values and the calculations leading to external rotor diameter are well established in the literature [3,12,14]. Therefore, the procedure presented in this paper assumes the rotor's external diameter as an input (or imposed) parameter, calculated previously by the designer or known by experience.

Once the design specifications, presented in Table 1, and the rotor's external diameter are known, the designer can move on to rotor sizing, as the flowchart of Figure 4 shows. The numbers nearby each block correspond to the design steps (which match the equations numbers) presented in Section 2.3. The designer needs to impose several parameters because the number of variables concerning an electrical machine design overcomes the number of independent equations. The values of all 33 imposed parameters used in the 
design employed as an example are presented in Table 2, as well as their suggested ranges and initial estimations.

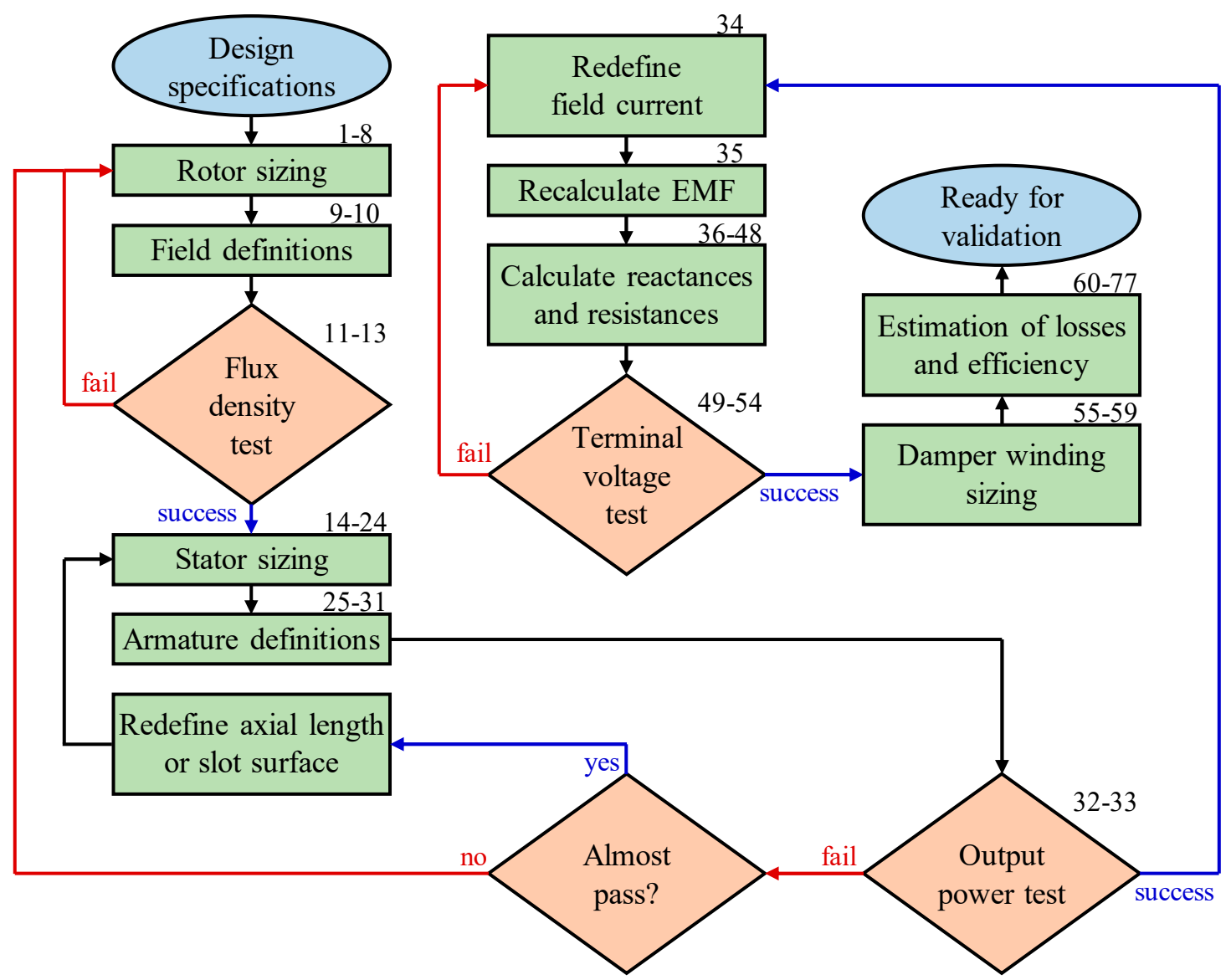

Figure 4. General flowchart of the proposed design methodology. The numbers alongside each block correspond to equation numbers of Section 2.3 .

After dimensioning the rotor, the surface reserved to field winding is known, which allows the definition of field conductor surface and its number of turns. If the core reluctance is neglected, the flux produced by the field can be calculated (even if the stator dimensions are not yet determined), considering only the air-gap and the generator's axial length. The flux density in the pole body $B_{P B}$, then, can be estimated.

At this point, the designer must be sure that $B_{P B}$ is acceptable. If not, it is necessary to change some imposed parameters, such as $K_{P B}$ (pole body factor that influences the pole body width). If redefining these parameters does not provide an appropriate shape, e.g., pole body very tall and narrow, the solution could rely on redefining the external rotor diameter $D_{R e}$.

After some adjustments to keep $B_{P B}$ within a desired range, the design proceeds through stator sizing, as shown in Figure 4 . Then, after dimensioning the slots, the armature can be defined, which provides the number of turns needed to accomplish the voltage requirement and the armature conductor surface, leading to the estimation of armature current and output power. Until this point of the design, the loading effects are not considered; then, it has been called a no-load design (Section 2.3.1).

The designer must observe if the output power is acceptable before moving to the full-load design (Section 2.3.2). If the power is different from its desired value $S_{E d}$, the armature current ought to be changed, which can be completed by redefining some imposed parameters, mainly, the machine axial length $L_{A}$, for minor changes, or increase the slot surface (adjusting the stator yoke to slot height factor $K_{S Y S}$ ) for major changes. If the geometry starts to become weird, the solution, again, would redefine $D_{R e}$. The designer 
may be inclined to change the armature current density $J_{A c}$; however, as this value is chosen to guarantee operation under the maximum allowable temperature, it cannot be changed without extra care. The same can be said about the tooth-to-slot width factor $K_{T S}$ because a tiny tooth may cause saturation or structural problems.

During load operation, the armature current affects the flux created by the rotor and, consequently, the terminal voltage. Three factors influence the load voltage: the resistance of armature conductor, the armature winding inductances, and armature reaction.

The resistive voltage drop is easily calculated, as the winding resistance is known from (40). However, the latter two reasons for voltage drops demand more attention.

In order to take into account these voltage drops caused by the armature current, the direct axis and quadrature axis reactances, $X_{d}$ and $X_{q}$, should be obtained. It is not a simple task to calculate these reactances from machine dimensions by analytical methods because the air-gap geometry is very complex in salient-pole machines, which would provide inaccurate results [3]. The proposed procedure obtains the values of $X_{d}$ and $X_{q}$ from finite-element simulation. The effect of the end-windings leakage inductance, which is not considered in 2D simulations, is then calculated analytically and included in the inductances obtained from simulation.

If the self-inductance of two phases in series $L_{2 p s}$ has only the second-order harmonic and the DC components different from zero, the direct axis inductance can be considered as half of $L_{2 p s}$ maximum value, whereas the quadrature axis inductance can be approximated as half of $L_{2 p s}$ minimum value [17]. Other methods to obtain the inductances from finite element simulations can be found in $[16,18]$, whereas their calculation by analytical procedures is presented in $[19,20]$.

Once the no-load induced voltage $E_{A n}$ is known, the voltage drops caused by the armature current should be calculated in order to obtain the terminal voltage $V_{T}$. The value of $V_{T}$ should be compared with its desired value $V_{T d}$. At this point of the design process, all generator geometry is defined, and the adjustment of terminal voltage must be accomplished by setting an appropriate value for the field current $I_{F}$, as shown in Figure 4 .

When the terminal voltage matches its desired value, the next steps include sizing the damper winding and estimating the losses to compute the generator efficiency. The damper bars have the objectives of reducing space $\mathrm{mmf}$ harmonics and improving performance during transients by creating torque against variations in rotation. The proposed design procedure takes into account copper losses in armature and field windings (as transients and harmonics are not modeled, the losses in damper bars are not considered). The iron losses are estimated in the stator core, but the iron losses in the rotor are not considered for the same reasons as the losses in damper bars. The windage (losses due to the moving parts of the machine) and ventilation losses (usually small-size synchronous generators have ventilators coupled to the shaft) are accounted, but friction losses in the bearings are not. The reason for not considering the bearing losses is the difficulty of determining the required parameter, such as the mass of the turbine and axial water push. The effect of misplacing these parameters could cause more harm than neglecting bearing losses.

After the estimation of the efficiency, if the designer finds it is suitable, the obtained synchronous generator is ready to be verified by finite element simulation. Such a simulation can confirm if the design specifications are attained.

Table 1. Design specifications.

\begin{tabular}{cccc}
\hline Symbol & Unit & Description & Value \\
\hline$S_{E d}$ & $\mathrm{VA}$ & Desired Output Power & 15,000 \\
$V_{T d}$ & $\mathrm{~V}$ & Desired Terminal Voltage & 400 \\
$P F$ & - & Power Factor & 0.9 \\
$f$ & $\mathrm{~Hz}$ & Electrical frequency & 50 \\
$n$ & $\mathrm{rpm}$ & Rotation & 1000 \\
\hline
\end{tabular}


Table 2. Imposed parameters.

\begin{tabular}{|c|c|c|c|}
\hline Symbol & Unit & Suggested Values ${ }^{1} /$ Ranges & Value \\
\hline$D_{R e}$ & $\mathrm{~mm}$ & 2 & 250 \\
\hline$K_{\alpha P}$ & - & $1 / 2-5 / 6$ & $2 / 3$ \\
\hline$K_{P B}$ & - & $1 / 3-3 / 4$ & $4 / 11$ \\
\hline$K_{P S S}$ & - & $0.12-0.2$ & 0.15 \\
\hline$I_{\text {Fmax }}$ & A & $4-7.5$ & 5 \\
\hline$J_{F}$ & $\mathrm{~A} / \mathrm{mm}^{2}$ & $2-3.5[1]$ & 3 \\
\hline$K_{F f}$ & - & $0.5-0.9$ & 0.8 \\
\hline$L_{A G}$ & & $\approx 1.5 / 100$ of $D_{R e^{3}}$ & 3.5 \\
\hline$L_{A}$ & $\mathrm{~mm}$ & 2 & 200.2 \\
\hline$K_{A G}$ & - & 0.95-1.15 & 1.023 \\
\hline$I_{F n l}$ & A & $\approx 50 \%$ of $I_{F_{\text {max }}}$ & 2.5 \\
\hline$W_{S o}$ & - & 4 & 2 \\
\hline$h_{S o}$ & $\mathrm{~mm}$ & $\approx W_{S o}$ & 2 \\
\hline$h_{S w}$ & $\mathrm{~mm}$ & 5 & 2.24 \\
\hline$K_{T S}$ & - & $0.85-1.15$ & 1 \\
\hline$K_{P B S Y}$ & - & $0.5-1.5$ & $4 / 5$ \\
\hline$K_{S Y S}$ & - & $1 / 3-5 / 6$ & 0.692 \\
\hline$K_{A c}$ & - & $5 / 6$ or $2 / 3$ & $5 / 6$ \\
\hline$N_{S}$ & slots & 6 & 36 \\
\hline$N_{C s}$ & paths & number of poles & 6 \\
\hline$N_{S l}$ & layers & 1 or 2 & 2 \\
\hline$\Delta \varnothing_{l}$ & - & $0.75-0.95[2]$ & 0.89 \\
\hline$K_{S f}$ & - & $1 / 3-2 / 3^{7}$ & 0.5 \\
\hline$I_{F n l}$ & A & 8 & 2.5 \\
\hline$I_{F}$ & A & 8 & 4.78 \\
\hline$r_{A k m}$ & $\Omega / \mathrm{km}$ & 9 & 3.92 \\
\hline$r_{F k m}$ & $\Omega / \mathrm{km}$ & 10 & 10.30 \\
\hline$J_{A}$ & $\mathrm{~A} / \mathrm{mm}^{2}$ & $4-6.5[1]$ & 5 \\
\hline$K_{m}$ & - & $1 / 3-1 / 1$ & $4 / 5$ \\
\hline$K_{D p}$ & - & $0.8-0.9$ or $1.1-1.2$ [1] & 0.8 \\
\hline$K_{D s}$ & - & $0.1-0.3[1]$ & 0.1 \\
\hline$p_{h}$ & $\mathrm{~W} / \mathrm{kg}$ & $1.656[21]$ & 1.656 \\
\hline$p_{f}$ & $\mathrm{~W} / \mathrm{kg}$ & $0.698[21]$ & 0.698 \\
\hline
\end{tabular}

1 These suggestions regard authors' recommendations to perform academic designs of generators with power between 5 and $200 \mathrm{kVA}$. Designers intended to design commercial generators must look for the best parameters to achieve their goal, respecting their production limits. ${ }^{2}$ Difficult to suggest values as they depend on the generator power. ${ }^{3}$ Larger machines usually have a shorter air-gap length. ${ }^{4}$ Must be larger enough to insert the coils. 5 Adjusted to keep the inclination angle of the slot wedge between $20^{\circ}$ and $40^{\circ}$. ${ }^{6}$ Recommended to be chosen in order to make $N_{C p p}$ integer. ${ }^{7}$ The slot fill factor is the fraction of the slot surface occupied by copper (here, only the copper surface was considered, without insulation); generally, small slots allow lower fill factors. Its exact value depends on many factors, including the manufacturing process, but 0.5 is a reasonable initial guess 8 Adjusted to keep terminal voltage close to its desired value, either under no-load or full-load operation. ${ }^{9}$ Resistance of 10 wires AWG 18 in parallel with 2 wires AWG 20 at $20{ }^{\circ} \mathrm{C} .{ }^{10}$ Resistance of AWG 15 at $20{ }^{\circ} \mathrm{C}$.

\subsection{Step-by-Step Design Procedure}

This section describes the proposed step-by-step procedure to design salient-pole wound-rotor synchronous generators. The main geometric parameters of the generator are shown in Figure 5, where the diameters and the air-gap are presented in Figure 5a; the pole dimensions in Figure 5b; the pole pitch, the slot pitch, the angle of one slot at the top, and stator yoke in Figure 5c; and the slot dimensions in Figure 5d. All variables presented in Figure 5 are described in the following paragraphs. 


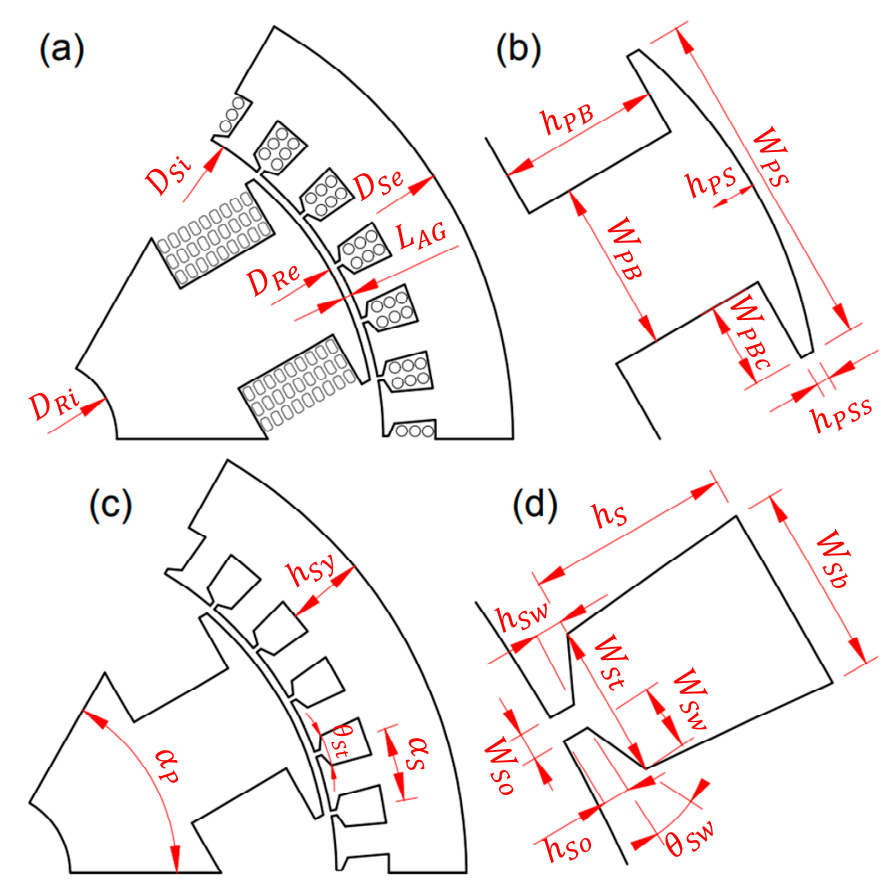

Figure 5. Main geometric parameters of the generator: (a) air-gap and diameters, (b) pole dimensions, (c) stator yoke and angles, and (d) slot dimensions.

The complete procedure is detailed within the 77 steps in Sections 2.3.1 and 2.3.2. The numbering of the steps coincides with the equations'number and with those presented in Figure 4.

\subsubsection{No-Load Design}

As presented in Section 2.2, the proposed procedure takes into account at first the no-load flux, and after, the load effects are included. The no-load design is composed of the rotor design and the stator design.

\section{Rotor Design}

The design begins as simple as by calculating the number of poles $P$, which is obtained from the electrical frequency $f(\mathrm{~Hz})$ and the rotational speed $\omega(\mathrm{rad} / \mathrm{s})$, both imposed by the designer/application requirements:

$$
P=\frac{120 \cdot f}{\omega} .
$$

The arc-section height of pole shoes $h_{P S a}(\mathrm{~mm})$ is calculated from some imposed parameters: $D_{R e}(\mathrm{~mm})$, the pole pitch $\alpha_{P}\left({ }^{\circ}\right)$, and the pole pitch factor $K_{\alpha P}$ that defines the percentage of the pole pitch actually used by a pole:

$$
h_{P S a}=\frac{D_{R e}}{2}-\cos \left(\frac{K_{\alpha P}}{2} \cdot \alpha_{P}\right) \cdot \frac{D_{R e}}{2},
$$

from the result of previous step, it is possible to obtain the width of pole shoes $W_{P S}(\mathrm{~mm})$ :

$$
W_{P S}=2 \cdot \tan \left(\alpha_{P} \cdot \frac{k_{\alpha P}}{2}\right) \cdot\left(\frac{D_{R e}}{2}-h_{P S a}\right),
$$

then, the width of pole body $W_{P B}(\mathrm{~mm})$ can be defined as a function of $W_{P S}$, imposing the pole body factor $K_{P B}$ :

$$
W_{P B}=W_{P S} \cdot K_{P B} .
$$


The straight-section height of pole shoes $h_{P S_{s}}(\mathrm{~mm})$ is also related to an imposed factor named $K_{P S s}$ :

$$
h_{P S s}=D_{R e} \cdot \frac{K_{P S s}}{P},
$$

moreover, the sum of $h_{P S a}$ and $h_{P S s}$ gives the height of pole shoes:

$$
h_{P S}=h_{P S a}+h_{P S s} \text {. }
$$

The complementary width of pole body $W_{P B C}(\mathrm{~mm})$ is:

$$
W_{P B C}=\frac{W_{P S}-W_{P B}}{2},
$$

the height of pole body $h_{P B}(\mathrm{~mm})$ uses the apothem equation:

$$
h_{P B}=\frac{D_{R e}}{2}-h_{P S}-\frac{W_{P S}}{2} \cdot \tan \frac{\pi-\alpha_{P}}{2} .
$$

Imposing a value for maximum allowable field current $I_{F \max }(\mathrm{A})$ and the field current density $J_{F}\left(\mathrm{~A} / \mathrm{mm}^{2}\right)$ allows finding the surface of field conductor $S_{F}\left(\mathrm{~mm}^{2}\right)$ :

$$
S_{F}=\frac{I_{F m a x}}{J_{F}},
$$

which makes it possible to obtain the number of turns of the field winding $T_{F}$, imposing the field-winding fill factor $K_{F f}$ :

$$
T_{F}=h_{P B} \cdot W_{P B c} \cdot \frac{K_{F f}}{S_{F}} .
$$

The reluctance of the air-gap $R_{A G}(\mathrm{~A} \cdot \mathrm{e} / \mathrm{Wb})$ depends on $D_{R e}, \alpha_{P}$, air-gap length $L_{A G}$ $(\mathrm{mm})$, axial length of active material $L_{A}(\mathrm{~mm})$, and the air-gap factor $K_{A G}$, imposed by the designer:

$$
R_{A G}=\frac{L_{A G}}{\mu_{0} \cdot L_{A} \cdot K_{A G} \cdot \frac{D_{R e}}{2} \cdot K_{\alpha P} \cdot \frac{\alpha_{P}}{2}},
$$

if all core reluctances are neglected (including stator and rotor), and the value of no-load field current $I_{F n l}(\mathrm{~A})$ is imposed, the flux in the pole body $\varnothing_{P B}(\mathrm{~Wb})$ can be estimated by:

$$
\varnothing_{P B}=\frac{T_{F} \cdot I_{F n l}}{R_{A G} / 2}
$$

finally, the flux density in pole body $B_{P B}(\mathrm{~T})$ is obtained:

$$
B_{P B}=\frac{\varnothing_{P B}}{L_{A} \cdot W_{P B}} .
$$

Stator Design

Once the rotor design is finished and the designer is satisfied with the flux density in pole body, the design of the stator starts dimensioning its internal diameter $D_{S i}(\mathrm{~mm})$ :

$$
D_{S i}=D_{R e}+2 \cdot L_{A G}
$$

the diameter at the top of the slot $D_{S t}(\mathrm{~mm})$ can be obtained by defining values for the eight slot opening $h_{S o}(\mathrm{~mm})$ and the height of slot wedge $h_{S w}(\mathrm{~mm})$ :

$$
D_{S t}=D_{S i}+2 \cdot\left(h_{S o}+h_{S w}\right),
$$


the angle occupied by the top of one slot $\theta_{S t}\left(^{\circ}\right)$ can be defined by the slot pitch angle $\alpha_{S}$ and imposing the tooth-to-slot width factor $K_{T S}$ :

$$
\theta_{S t}=\frac{\alpha_{S}}{1+K_{T S}},
$$

then, the top of slot width $W_{S t}(\mathrm{~mm})$ is:

$$
W_{S t}=D_{S t} \cdot \tan \frac{\theta_{S t}}{2}
$$

imposing a value to the width of slot opening $W_{S_{o}}(\mathrm{~mm})$ leads to the width of slot wedge $W_{S w}(\mathrm{~mm})$ :

$$
W_{S w}=\frac{W_{S t}-W_{S o}}{2} .
$$

The pole body width to stator yoke factor $K_{P B S Y}$ is imposed to define the height of stator yoke $h_{S Y}(\mathrm{~mm})$ :

$$
h_{S Y}=W_{P B} \cdot K_{P B S Y},
$$

similarly, the height of the slot $h_{S}(\mathrm{~mm})$ is obtained from an imposed factor: the stator yoke to slot height factor $K_{S Y S}$ :

$$
h_{S}=h_{S Y} \cdot K_{S Y S},
$$

in order to keep the teeth parallel (same weights at top and bottom), the inclination angle of the slot edge $\theta_{S e i}\left({ }^{\circ}\right)$ must be:

$$
\theta_{\text {Sei }}=\frac{\alpha_{S}}{2} \text {. }
$$

The bottom of slot width $W_{S b}(\mathrm{~mm})$ is defined by:

$$
W_{S b}=W_{S t}+2 \cdot h_{S} \cdot \tan \theta_{S e i},
$$

and the external diameter of stator $D_{S e}(\mathrm{~mm})$ is obtained by:

$$
D_{S e}=D_{S t}+2 \cdot h_{S}+2 \cdot h_{S Y},
$$

as the slot is trapezoidal, its surface $S_{s}\left(\mathrm{~mm}^{2}\right)$ is:

$$
S_{S}=h_{S} \cdot \frac{W_{S b}+W_{S t}}{2} .
$$

The armature coil pitch $\alpha_{A c}\left(^{\circ}\right)$ is calculated after imposing a value for the armature coil-shortening factor $K_{A c}$ :

$$
\alpha_{A c}=\alpha_{P} \cdot K_{A c} \cdot \frac{P}{2},
$$

as the coil is shortened, the flux linked by the armature coil should be decreased by the reduction factor due to coil shortening $\Delta \varnothing_{C_{S}}[1]$ :

$$
\Delta \varnothing_{C S}=\sin \frac{\alpha_{A c}}{2} .
$$

The number of coils per pole and per phase $N_{C p p}$ can be calculated using the number of slots $N_{S}$ and the number of layers in a slot $N_{S l}$, both imposed:

$$
N_{C p p}=\frac{N_{S} \cdot N_{S l}}{6 \cdot P} .
$$

As the winding is not concentrated, a reduction factor due to winding distribution $\Delta \varnothing_{W d}$ should be used [1]:

$$
\Delta \varnothing_{W d}=\frac{\sin \frac{N_{C p p} \cdot \alpha_{S}}{2}}{N_{C p p} \cdot \sin \frac{\alpha_{S}}{2}} .
$$


The number of turns of armature winding per phase $T_{A}$ is obtained considering the desired terminal voltage $V_{T d}(\mathrm{~V})$ and reduction factor due to leakage flux $\Delta \varnothing_{l}$, as part of the flux produced by the field never reaches armature windings [2]:

$$
T_{A}=\frac{\frac{V_{T d}}{\sqrt{3}}}{\sqrt{2} \cdot \pi \cdot f \cdot \Delta \varnothing_{l} \cdot \Delta \varnothing_{C s} \cdot \Delta \varnothing_{W d} \cdot \varnothing_{P B}},
$$

defining the number of coils in series per phase $N_{C_{S}}$, the number of turns of armature winding per coil $T_{A}$ is:

$$
T_{A c}=\frac{T_{A}}{N_{C p p} \cdot N_{C s}}
$$

the slot fill factor $K_{S f}$ defines the armature conductor surface:

$$
S_{A c}=\frac{S_{s} \cdot K_{S f}}{T_{A c} \cdot N_{S l}}
$$

If the armature current density $J_{A}\left(\mathrm{~mm}^{2}\right)$ is imposed, the allowable armature current $I_{A}(\mathrm{~A})$ is:

$$
I_{A}=S_{A c} \cdot J_{A}
$$

Once the desired terminal voltage and the armature current are known, the electrical output power $S_{E}$ (VA) supported by the generator is:

$$
S_{E}=\sqrt{3} \cdot I_{A} \cdot V_{T d}
$$

The electrical output active power $P_{E}(\mathrm{~W})$ can be obtained considering a desired power factor $P F$.

\subsubsection{Full-Load Design}

The pole-body flux during no-load operation has been calculated in (12). Using a new value of field current $I_{F n}(\mathrm{~A})$, the pole-body flux can be recalculated for nominal operation:

$$
\varnothing_{P B n}=\frac{T_{F} \cdot I_{F n}}{R_{A G} / 2}
$$

then, the phase-to-neutral EMF in nominal load $E_{A n}(\mathrm{~V})$ is:

$$
E_{A n}=\sqrt{2} \cdot \pi \cdot T_{A} \cdot f \cdot \Delta \varnothing_{l} \cdot \Delta \varnothing_{C S} \cdot \Delta \varnothing_{W d} \cdot \varnothing_{P B n} .
$$

The next step is calculating the armature winding resistance per phase, which depends on the armature winding length. The arc length between two slots of the same coil $d_{S}(\mathrm{~mm})$ is:

$$
d_{S}=\left(D_{S t}+h_{S}\right) \cdot \frac{\alpha_{A c}}{P}
$$

assuming that the coil end has the shape of a half-circle, its length is:

$$
L_{C e}=\pi \cdot \frac{d_{s}}{2},
$$

the total length of an armature coil turn $L_{A t}(\mathrm{~mm})$ is then:

$$
L_{A t}=2 \cdot L_{C e}+2 \cdot L_{A}
$$

finally, using the resistance per $\mathrm{km}$ of the armature conductor $r_{k m}$, the phase armature resistance $R_{\text {Aref }}(\Omega)$ can be obtained:

$$
R_{\text {Aref }}=L_{C e} \cdot T_{A} \cdot r_{k m} \cdot 10^{-6},
$$


usually, tables of wires are referred to $20^{\circ} \mathrm{C}$ or $25^{\circ} \mathrm{C}$; to correct the resistance value, the wire resistance should be referred to the operating temperature [3]:

$$
R_{A}=R_{\text {Aref }} \cdot \frac{243.5+T_{o p}}{243.5+T_{\text {ref }}},
$$

where $T_{o p}\left({ }^{\circ} \mathrm{C}\right)$ is the operating temperature, considered as $100{ }^{\circ} \mathrm{C}$, and $T_{r e f}$ is the reference temperature $\left(20^{\circ} \mathrm{C}\right)$ related to the wire resistance.

The field resistance referred to $20^{\circ} \mathrm{C}$ can be obtained using the resistance per kilometer of the field conductor $r_{F k m}(\Omega / \mathrm{km})$ :

$$
R_{\text {Fref }}=L_{F c} \cdot T_{F} \cdot r_{F k m} \cdot 10^{-6},
$$

where $L_{F c}(\mathrm{~mm})$ is the total length of the field winding, obtained from:

$$
L_{F c}=2 \cdot \pi \cdot \frac{W_{P B}+W_{P B c}}{2}+2 \cdot L_{A} .
$$

Similarly to the armature resistance $(\Omega)$, the field resistance should be referred to the operating temperature:

$$
R_{F}=R_{\text {Fref }} \cdot \frac{243.5+T_{o p}}{243.5+T_{\text {ref }}} .
$$

At this point, $X_{d}$ and $X_{q}$ must be known. Although they could be calculated from analytical equations, here, they are obtained from numerical simulation, as described in Section 2.2. However, as the simulations were performed in $2 \mathrm{D}$, the leakage flux in armature end-windings is not considered. The inductance that represents this behavior can account for a significant portion of the total machine leakage inductance, especially in generators applied for direct-driven wind turbines, usually with great diameter and short stack length. To take the effect of end-windings leakage flux, [3] suggests the following calculations:

$$
L_{\text {end }}=\mu_{0} \cdot L_{C e} \cdot T_{A c}^{2} \cdot\left(\ln \frac{8 \cdot L_{C e}}{R_{C e}}-2\right),
$$

where $R_{C e}(\mathrm{~mm})$ is the geometric mean distance of the coilside from itself, obtained by:

$$
R_{C e}=0.447 \cdot \sqrt{\frac{S_{S}}{N_{S l}}} .
$$

Equation (44) provides the leakage inductance of a single coil end, the total endwinding inductance $(\mathrm{H})$, considering the mutual inductances can be obtained by using a factor $K_{m}$ that estimates the percentage of flux that is linked by two adjacent end coils. Here, such a factor is considered $4 / 5$ because the coil pitch is 5 slots and the two coils of each group share $4 / 5$ of it, as shown in Figure 3. The total end-winding inductance is then [3]:

$$
L_{\text {Tend }}=N_{C S} \cdot\left[1+\left(N_{C p p}-1\right) \cdot K_{m}\right] \cdot L_{\text {end }} .
$$

Therefore, the value of $L_{\text {Tend }}$ should be added to both $L_{d}$ and $L_{d}$, for which values could be found by finite element simulation, as described in Section 2.2. To accomplish this, the generator has been simulated with two phases in series, and the inductance of this winding $L_{2 p s}$ has been obtained as a function of rotor position-its maximum and minimum values correspond to twice the value of $L_{d}$ and $L_{q}$, respectively. The conductors of the field and the remaining phase have been taken out of the simulation, whereas the winding of the two phases in series has been excited with nominal armature current. The values of $X_{d}$ and $X_{q}$ are obtained by:

$$
X_{d}=2 \cdot \pi \cdot f \cdot\left(L_{d}+L_{\text {Tend }}\right),
$$




$$
X_{q}=2 \cdot \pi \cdot f \cdot\left(L_{q}+L_{\text {Tend }}\right) .
$$

The generator phasor diagram is presented in Figure 6.

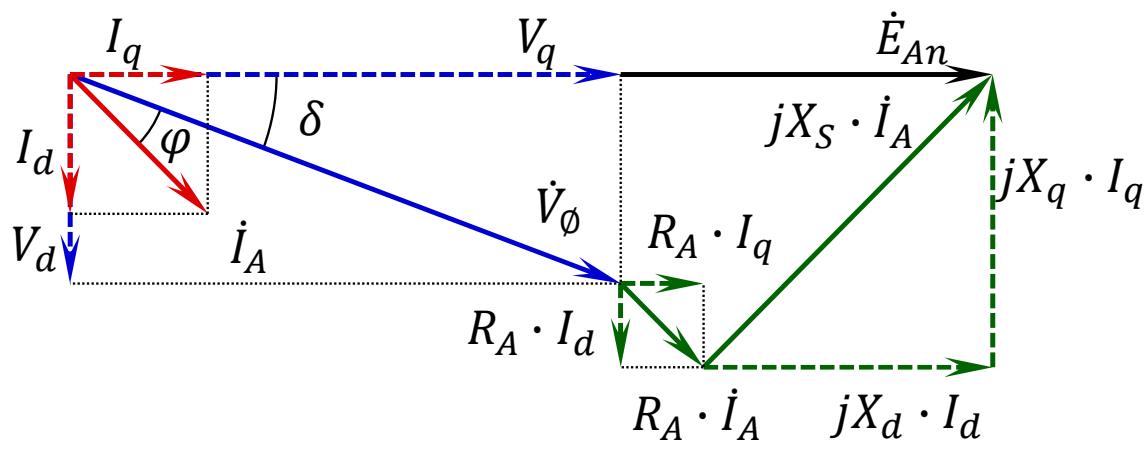

Figure 6. Generator phasor diagram.

From Figure 6, the following relations can be established:

$$
\begin{gathered}
\delta=\tan ^{-1} \frac{I_{A} \cdot X_{q} \cdot \cos \varphi-I_{A} \cdot R_{A} \cdot \sin \varphi}{I_{A} \cdot X_{q} \cdot \sin \varphi+I_{A} \cdot R_{A} \cdot \cos \varphi+\frac{V_{T d}}{\sqrt{3}}}, \\
I_{d}=I_{A} \cdot \sin (\varphi+\delta), \\
I_{q}=I_{A} \cdot \cos (\varphi+\delta), \\
V_{d}=X_{q} \cdot I_{q}-R_{A} \cdot I_{d}, \\
V_{q}=E_{A n}-X_{d} \cdot I_{d}-R_{A} \cdot I_{q}, \\
V_{T}=\sqrt{3} \cdot \sqrt{V_{d}^{2}+V_{q}^{2}},
\end{gathered}
$$

where $\delta$ is the load angle, $\varphi$ is the displacement angle between voltage and current, $V_{T d}$ is the desired value of terminal voltage equal to $\sqrt{3} \cdot V_{\varphi}, I_{d}$ and $I_{q}$ are the armature current components of direct and quadrature axes, $V_{d}$ and $V_{q}$ are the voltage components on direct and quadrature axes, and $V_{T}$ is the phase-to-phase terminal voltage.

An implicit loop is formed from (49)-(54) as (49) depends on terminal voltage, and the terminal voltage depends on armature current, which needs the load angle to be calculated. The proposed solution to solve it without numerical methods is to impose the desired value of the terminal voltage in (49). These equations make sense if, and only if, the terminal voltage obtained from (54) equals its desired value, which can be accomplished by choosing a proper value for $I_{F n}$. Such an iterative process is usually finished after few attempts. Once the terminal voltage is obtained and matches its desired value, the design flow (Figure 4) leads to damper-winding sizing.

In order to avoid flux harmonics, the damper winding pitch $\alpha_{D}$ (angle between damper bars) should not match the stator slot pitch $\alpha_{S}$ [1,2]. In spite of the existence of methods to determine the damper winding pitch [2], it is possible to impose a factor $K_{D p}$ to obtain it from the slot pitch:

$$
\alpha_{D}=\alpha_{S} \cdot\left(1-K_{D p}\right) .
$$

The number of damper bars per pole can be obtained from [2]:

$$
N_{P d b}=\frac{\alpha_{P} \cdot K_{\alpha P}}{\alpha_{D}},
$$

if $N_{P d b}$ is not an integer, its value should be rounded, avoiding extrapolating the limits of $K_{D p}$. 
The total copper surface of the damping winging $\left(\mathrm{mm}^{2}\right)$ can be determined as a fraction of the total armature surface [1], which can be obtained as:

$$
S_{A t}=S_{S} \cdot N_{S} \cdot K_{S f}
$$

then, the surface of each damper bar is $\left(\mathrm{mm}^{2}\right)$ :

$$
S_{D b}=\frac{S_{A t} \cdot K_{D s}}{N_{P d b} \cdot P}
$$

where $K_{D s}$ is a factor that defines the damper bars surface as a fraction of total copper of armature.

Finally, the diameter of the damper bars $(\mathrm{mm})$ is calculated as:

$$
D_{D b}=\sqrt{\frac{4}{\pi} \cdot S_{D b}}
$$

The next step is to estimate the losses. The first one, which is the most simple, is the copper loses present in the armature $\left(\rho_{A c}\right)$ and field $\left(\rho_{F c}\right)$ windings:

$$
\begin{gathered}
\rho_{A c}=3 \cdot R_{A} \cdot I_{A}^{2}, \\
\rho_{F c}=R_{F} \cdot I_{F}^{2} .
\end{gathered}
$$

Iron losses calculation represents a more difficult task. The estimation of these losses relies on material characteristics that are represented by their known losses per kilogram of material (provided by the datasheets of the laminations). The first step is to calculate the volume of magnetic steel.

The volume of steel in stator yoke is:

$$
V_{S y}=\frac{\pi}{4} \cdot L_{A} \cdot\left[D_{S e}^{2}-\left(D_{S e}-2 \cdot h_{S y}\right)^{2}\right]
$$

and the volume of rotor teeth is:

$$
V_{S t}=L_{A} \cdot N_{S} \cdot\left[W_{T} \cdot h_{S}+\left(W_{T}+2 \cdot W_{S w}\right) \cdot h_{S o}+\left(W_{T}+W_{S w}\right) \cdot h_{S w}\right],
$$

where $W_{T}$ is the width of a tooth, obtained as:

$$
W_{T}=D_{S t} \cdot \tan \left(\frac{\alpha_{S}-\theta_{S t}}{2}\right)
$$

The masses of steel in stator yoke and teeth can be obtained, respectively, by:

$$
\begin{aligned}
& m_{S y}=V_{S y} \cdot d_{F e}, \\
& m_{S t}=V_{S t} \cdot d_{F e},
\end{aligned}
$$

where $d_{F e}$ is the mass density of the iron, considered as $7.7 \mathrm{~g} / \mathrm{cm}^{3}$.

The method chosen to estimate the iron losses is derived from [21] and uses the losses per kilogram due to hysteresis $p_{h}$ and Foucault $p_{f}$. This method also uses empirical factors to account for hysteresis losses in the stator yoke $K_{S y h}(2.0)$ and teeth $K_{S t h}(1.2)$, and Foucault losses in the stator yoke $K_{S y f}(1.8)$ and teeth $K_{S t f}(2.5)$.

The hysteresis loss in the stator yoke is:

$$
\rho_{S y h}=K_{S y h} \cdot m_{S y} \cdot p_{h} \cdot \frac{f}{50} \cdot\left(\frac{B_{S y}}{1.5}\right)^{2},
$$


where $B_{S y}$ is the peak of flux density in stator yoke. It can be approximated by:

$$
B_{S y}=B_{P B} \cdot \frac{h_{S y}}{W_{P B}} \cdot \Delta \varnothing_{l} .
$$

Similarly, Foucault loss in stator yoke is:

$$
\rho_{S y f}=K_{S y f} \cdot m_{S y} \cdot p_{f} \cdot \frac{f}{50} \cdot\left(\frac{B_{S y}}{1.5}\right)^{2},
$$

and both hysteresis and Foucault losses in the teeth are, respectively:

$$
\begin{aligned}
& \rho_{S t h}=K_{S t h} \cdot m_{S t} \cdot p_{h} \cdot \frac{f}{50} \cdot\left(\frac{B_{S t}}{1.5}\right)^{2}, \\
& \rho_{S t f}=K_{S t f} \cdot m_{S t} \cdot p_{f} \cdot \frac{f}{50} \cdot\left(\frac{B_{S t}}{1.5}\right)^{2},
\end{aligned}
$$

where $B_{S t}$ is the peak value of the flux density in teeth, which can be approximated by:

$$
B_{S t}=\frac{B_{P B}}{1-\frac{\theta_{S t}}{\alpha_{S}}} \cdot \Delta \varnothing_{l} .
$$

The values obtained from (68) and (72) can be used to estimate the flux densities in stator yoke and teeth based on the flux in pole body (13) as a first approximation. A design refinement can substitute these values after simulations by finite element under load operation.

Windage and ventilator losses $(\mathrm{W})$ can be estimated by [1]:

$$
\rho_{W V}=K_{S t f} \cdot D_{R e} \cdot\left(L_{A}+0.6 \cdot \tau_{P}\right) \cdot v_{R}^{2}
$$

where $K_{S t f}$ is an experimental factor for windage and ventilation losses, suggested as $10 \mathrm{~W} \cdot \mathrm{s}^{2} / \mathrm{m}^{4}$ by [1], $\tau_{P}(\mathrm{~mm})$ is the arc length of a pole pitch, given by:

$$
\tau_{P}=\frac{\pi \cdot D_{R e}}{P}
$$

and $v_{r}(\mathrm{~m} / \mathrm{s})$ is the surface speed of the rotor:

$$
v_{r}=n \cdot \frac{D_{R e}}{2} .
$$

Stray losses can be estimated as a factor of total losses, [1] which suggests values between $0.1 \%$ and $0.2 \%$. Adopting $0.2 \%$, the total losses $(\mathrm{W})$ are obtained from:

$$
\rho_{T}=1.002 \cdot\left(\rho_{A c}+\rho_{F c}+\rho_{S y h}+\rho_{S y f}+\rho_{S t h}+\rho_{S t f}+\rho_{W V}\right) .
$$

Although the friction losses in the bearings are not included in (76), by the reasons explained in Section 2.2, the designer can estimate the bearing losses and account for them by adding a term in (76).

Finally, the efficiency can be obtained by:

$$
\eta=\frac{P_{e}}{P_{e}+\rho_{T}},
$$

and all design steps are completed. At this point, if the designer is satisfied with the design, numerical simulations should be carried out for further analysis and verification. 


\section{Results and Discussions}

In order to show how the design procedure works, it has been applied to perform a design of a synchronous generator, for which specifications are shown in Table 1.

All imposed parameters (designer choices) regarding the example design, as their suggested ranges, are shown in Table 2 . The suggestions presented here are only a guide for new designers; the best choices should rely on the designer's own experience. The application particularities and the design specifications ought to be considered in these choices.

The finite-element simulation was carried out to provide the values of $L_{d}$ and $L_{q}$ used in (47) and (48), respectively, as described in Section 2.2, resulting in the curve of $L_{2 p s}$, shown in Figure 7 . These values are presented in Table 3.

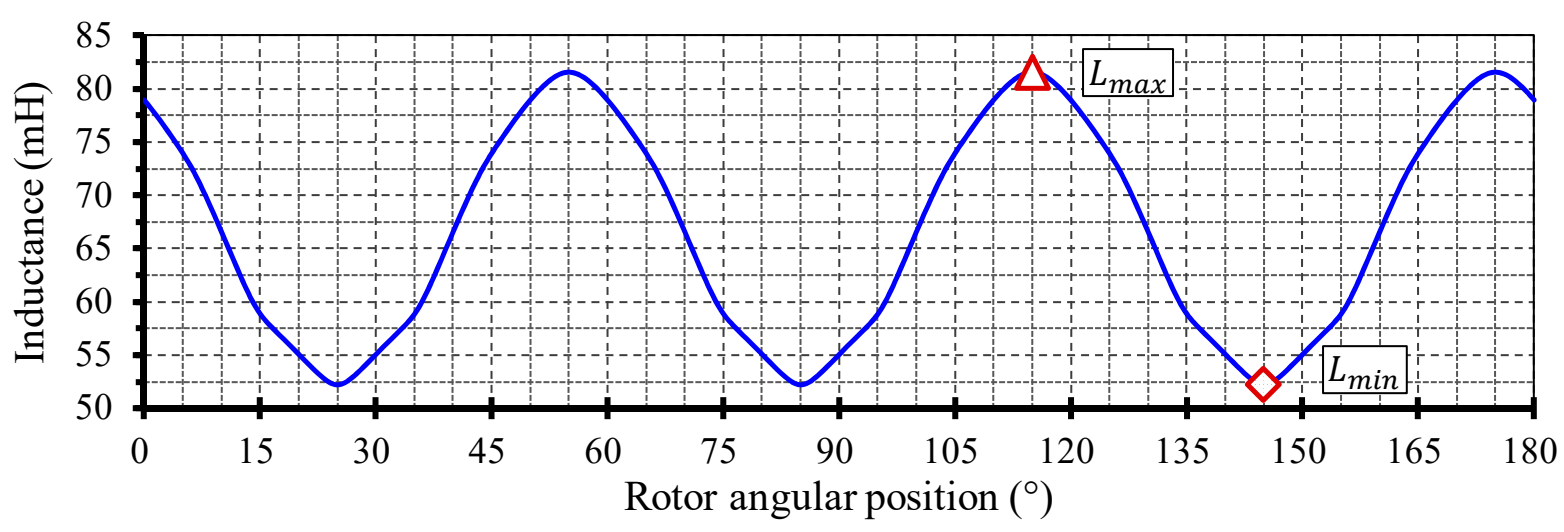

Figure 7. Inductance $L_{2 p s}$ obtained by finite element simulation.

Table 3. Generator main results.

\begin{tabular}{cccc}
\hline Symbol & Unit & Description & Value \\
\hline$P$ & poles & Number of poles & 6 \\
$W_{P S}$ & $\mathrm{~mm}$ & Width of pole shoes & 85.51 \\
$W_{P B}$ & $\mathrm{~mm}$ & Width of pole body & 31.09 \\
$h_{P S}$ & $\mathrm{~mm}$ & Height of pole shoes & 13.81 \\
$h_{P B}$ & $\mathrm{~mm}$ & Height of pole body & 37.14 \\
$S_{F}$ & $\mathrm{~mm}$ & Surface of field conductor & 1.67 \\
$T_{F}$ & turns & Field winding turns & 485 \\
$D_{S i}$ & $\mathrm{~mm}$ & Internal diameter of stator & 257 \\
$W_{S t}$ & $\mathrm{~mm}$ & Top of slot width & 11.59 \\
$W_{S b}$ & $\mathrm{~mm}$ & Bottom of slot width & 14.60 \\
$h_{S}$ & $\mathrm{~mm}$ & Height of the slot & 17.20 \\
$h_{S y}$ & $\mathrm{~mm}$ & Height of stator yoke & 24.87 \\
$D_{S e}$ & $\mathrm{~mm}$ & External diameter of stator & 349.6 \\
$N_{C p p}$ & $\mathrm{coils}$ & Number of coils per pole and per phase & 2 \\
$T_{A c}$ & $\mathrm{turns}$ & Number of turns per coil & 13 \\
$S_{A c}$ & $\mathrm{~mm}$ & Armature conductor surface & 4.33 \\
$D_{D b}$ & $\mathrm{~mm}$ & Diameter of damper bars & 4.64 \\
$N_{P d b}$ & $\mathrm{bars}$ & Number of damper bars per pole & 4 \\
$L_{d}$ & $\mathrm{mH}$ & Direct axis inductance 1 & 40.78 \\
$L_{q}$ & $\mathrm{mH}$ & Quadrature axis inductance & 26.10 \\
$L_{T e n d}$ & $\mathrm{mH}$ & End-winding inductance & 1.18 \\
$X_{d}$ & $\Omega$ & Direct axis reactance & 13.18 \\
$X_{q}$ & $\Omega$ & Quadrature axis reactance & 8.57 \\
$R_{A}$ & $\Omega$ & Armature resistance per phase 2 & 0.6275 \\
$R_{F}$ & $\Omega$ & Field resistance 2 & 3.80 \\
\hline
\end{tabular}

${ }^{1}$ Without considering the effect of end-winding leakage inductance, $L_{\text {Tend }}$ is taken into account in $X_{d}$ and $X_{q}$ by (47) and (48). ${ }^{2}$ Referred to $100{ }^{\circ} \mathrm{C}$. 
This machine is not optimized and surely does not match commercial machines comparing their torque density, volume, and active mass. However, a skilled designer can choose the imposed parameters with wisdom to improve his machine.

In this example, the imposed parameters have been chosen to provide a reliable result. As the design model has simplifications, some attention has been given to make results closer to the desired values, such as:

- As the iron core reluctance is neglected, the flux density has been kept low;

- Narrow slots have been avoided to minimize flux leakage.

A good security margin has been applied to field current, comparing its no-load value and the conductor capacity.

The main results are shown in Table 3.

The losses and the efficiency obtained from this example are presented in Table 4.

Table 4. Losses and efficiency obtained in the design.

\begin{tabular}{cccc}
\hline Symbol & Unit & Description & Value \\
\hline$\rho_{A c}$ & $\mathrm{~W}$ & Armature copper losses & 883.0 \\
$\rho_{F c}$ & $\mathrm{~W}$ & Field copper losses & 87.5 \\
$\rho_{S y h}$ & $\mathrm{~W}$ & Stator yoke core losses due to hysteresis & 45.6 \\
$\rho_{S y f}$ & $\mathrm{~W}$ & Stator yoke core losses due to Foucault & 17.3 \\
$\rho_{S t h}$ & $\mathrm{~W}$ & Stator teeth core losses due to hysteresis & 67.6 \\
$\rho_{S t f}$ & $\mathrm{~W}$ & Stator yoke core losses due to Foucault & 59.3 \\
$\rho_{W V}$ & $\mathrm{~W}$ & Windage and ventilation losses & 119.4 \\
$\rho_{T}$ & $\mathrm{~W}$ & Total losses & 1282.3 \\
$\eta$ & $\%$ & Estimated efficiency & 91.3 \\
\hline
\end{tabular}

The behavior of the designed generator under different load conditions can be observed in Table 5. These data have been obtained from the following procedure:

- A new magnitude of armature current is imposed in step 32, corresponding to $25 \%$, $50 \%, 75 \%, 100 \%$, and $125 \%$ loads;

- The value of the field current is adjusted to keep the terminal voltage constant at $400 \mathrm{~V}$;

- The values of direct and quadrature axis reactances, used in steps 49, 52, and 53, as well as the power factor, are considered constants;

- $\quad$ The load angle value, corresponding to each load condition, is calculated by (49).

Table 5. Behavior of the designed generator under different load conditions.

\begin{tabular}{cccc}
\hline Loading & Armature Current & Field Current & Load Angle \\
\hline $25 \%$ & $5.41 \mathrm{~A}$ & $2.94 \mathrm{~A}$ & $9.00^{\circ}$ \\
$50 \%$ & $10.83 \mathrm{~A}$ & $3.49 \mathrm{~A}$ & $16.19^{\circ}$ \\
$75 \%$ & $16.24 \mathrm{~A}$ & $4.11 \mathrm{~A}$ & $21.89^{\circ}$ \\
$100 \%$ & $21.66 \mathrm{~A}$ & $4.78 \mathrm{~A}$ & $26.43^{\circ}$ \\
$125 \%$ & $27.07 \mathrm{~A}$ & $5.47 \mathrm{~A}$ & $30.10^{\circ}$ \\
\hline
\end{tabular}

Figures 8 and 9 provide further information. The correspondence between the armature current and the field current is shown in Figure 9, regarding different load conditions, forming the " $\mathrm{V}$ " curves of the synchronous machine. Three lines are also plotted crossing these curves to inform usual power factors. 


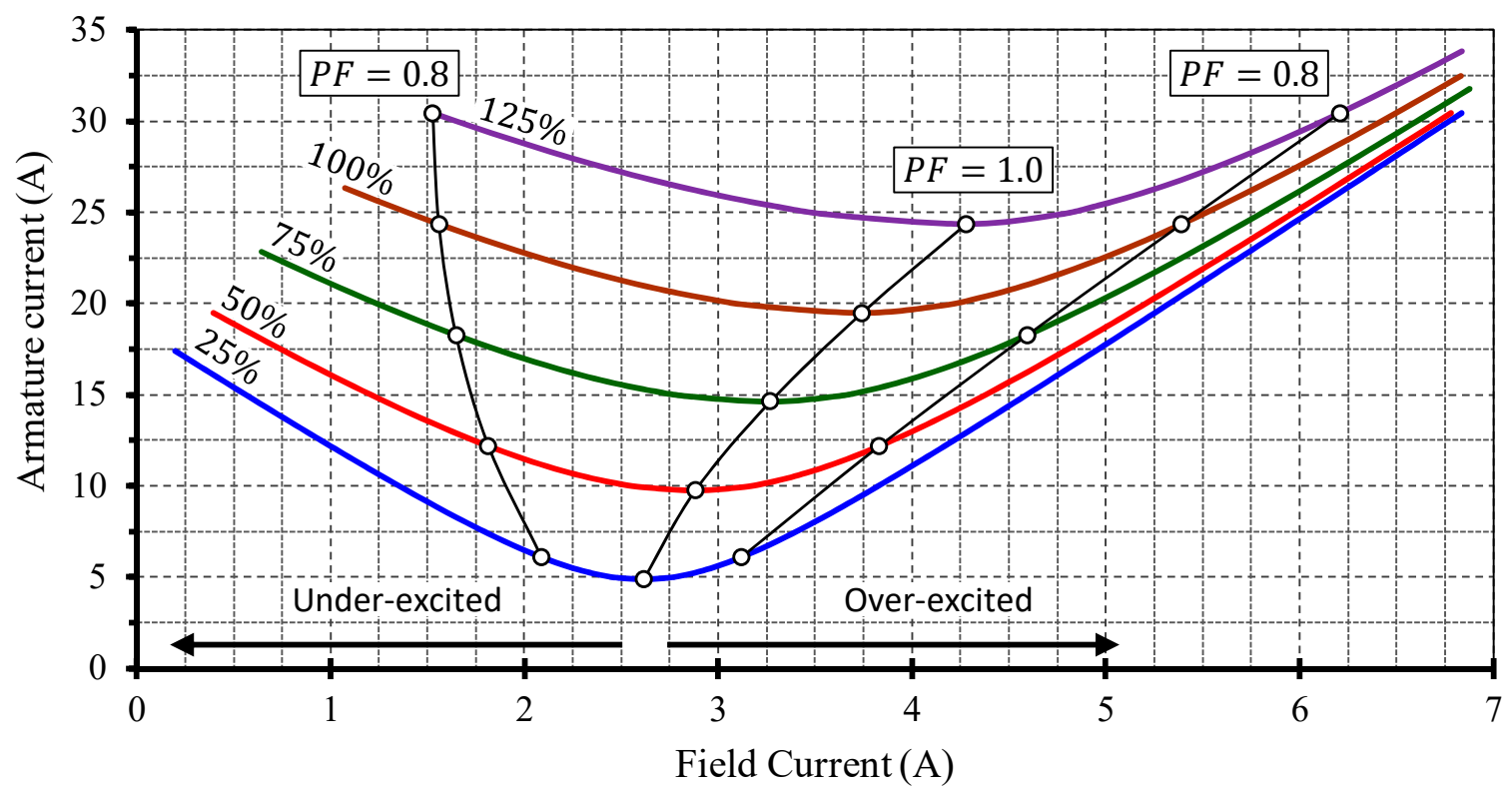

Figure 8. "V" curves of the resulting generator corresponding to different load conditions.

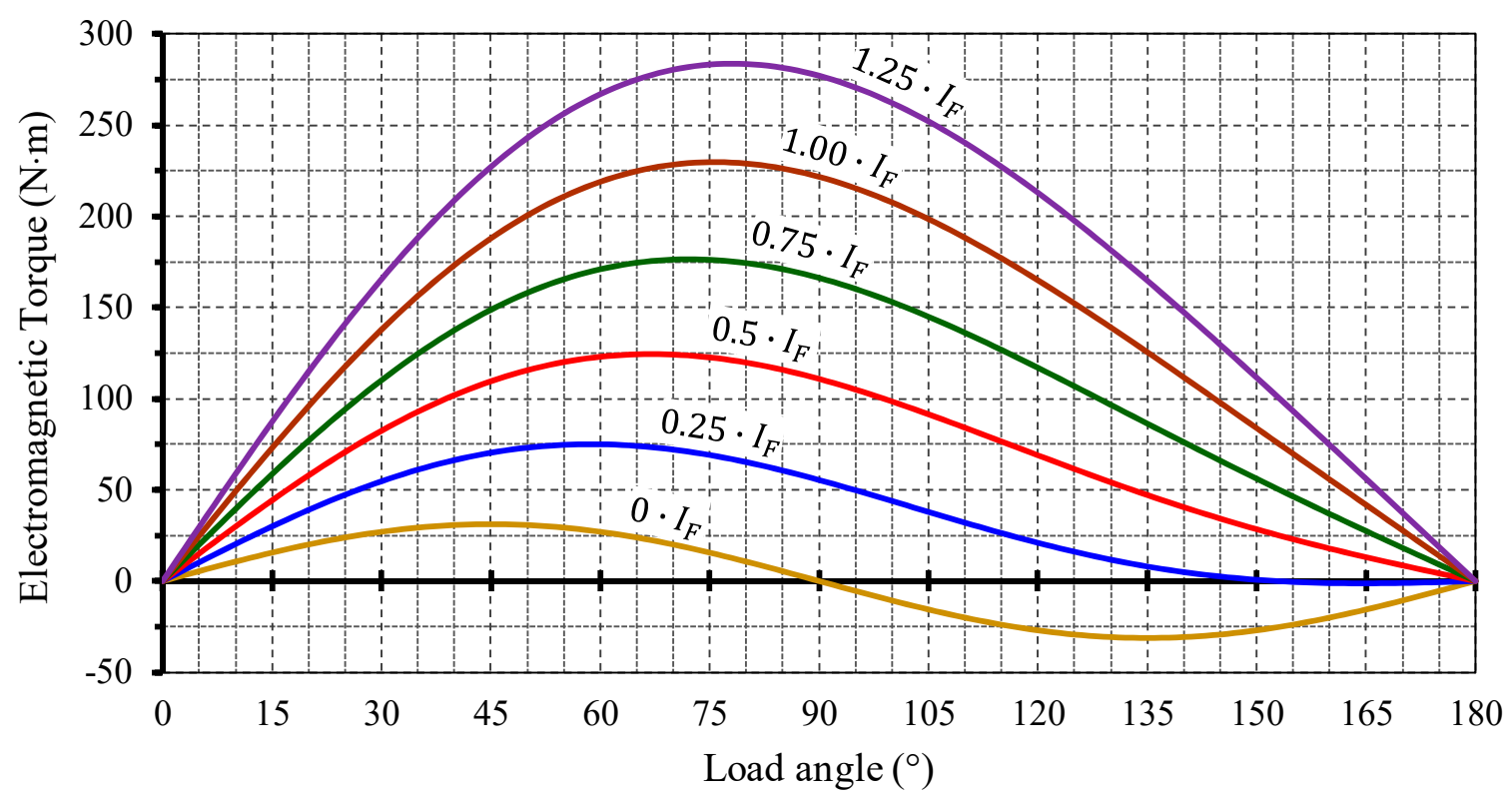

Figure 9. Electromagnetic torque as a function of load angle.

The electromagnetic torque, as a function of the load angle, is presented in Figure 9 for several values of the field current, from $0 \%$ to $125 \%$. These curves correspond to analytical approximations, where the armature resistance has been neglected, using [2]:

$$
T_{e}=\frac{3}{\omega} \cdot \frac{E_{A n} \cdot V_{\varnothing}}{X_{d}} \cdot \sin (\delta)+\frac{3}{2 \cdot \omega} \cdot V_{\varnothing}^{2} \cdot\left(\frac{1}{X_{q}}-\frac{1}{X_{d}}\right) \cdot \sin (2 \cdot \delta) .
$$

Finite-element simulations have been performed to help validate the design. The time-stepping simulations take into account the ferromagnetic saturation. The no-load and the full-load line flux and flux densities are presented in Figures 10 and 11, respectively. 


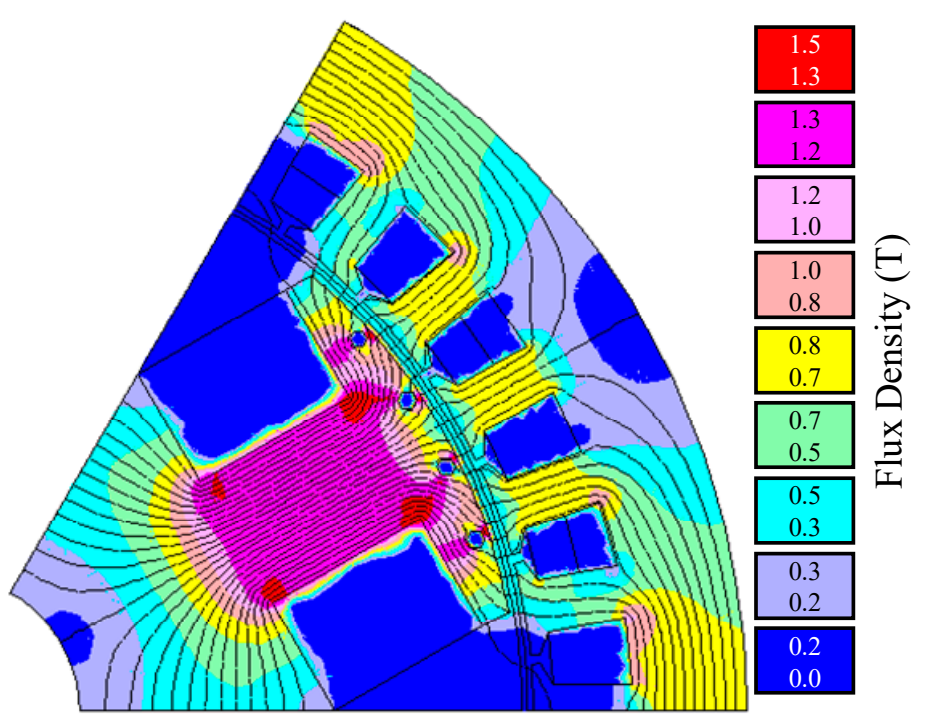

Figure 10. Finite-element solution of the magnetic field distribution and magnetic flux density under no-load operation.

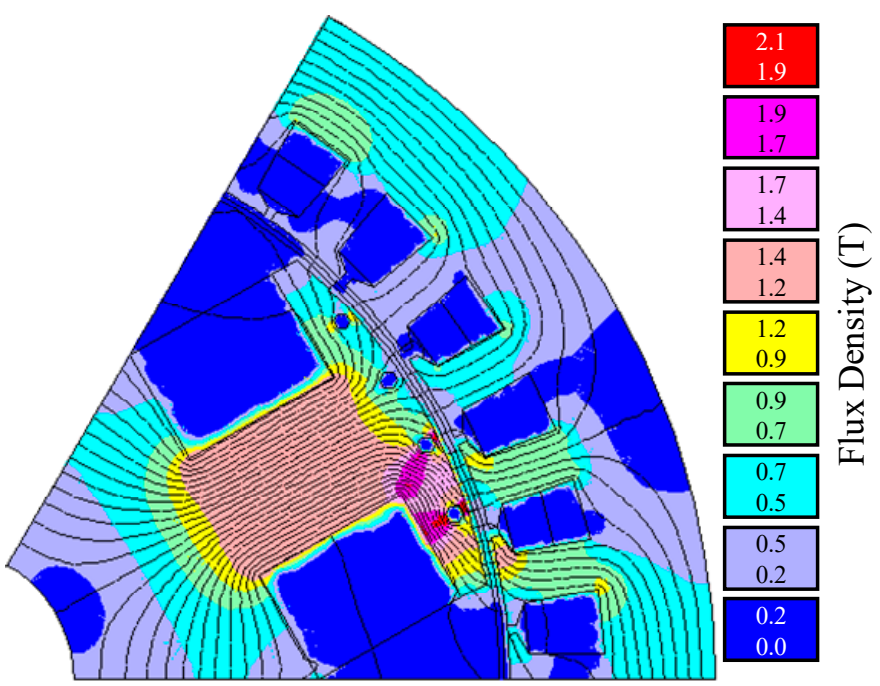

Figure 11. Finite-element solution of the magnetic field distribution and magnetic flux density under full-load operation.

The main electromagnetic results are presented in Table 6 . It can be observed that there is good agreement between the values obtained from the design model and those attained by simulations.

Table 6. Main electromagnetic results.

\begin{tabular}{ccccc}
\hline Symbol & Unit & Design & FEA & diff. (\%) \\
\hline$B_{P B}{ }^{1}$ & $\mathrm{~T}$ & 1.25 & 1.28 & -2.3 \\
$V_{T}$ & $\mathrm{~V}$ & 400.3 & 405.98 & -1.4 \\
$I_{A}$ & $\mathrm{~A}$ & 21.66 & 21.19 & +2.2 \\
$S_{E}{ }^{3}$ & $\mathrm{kVA}$ & 15.01 & 14.90 & +0.7 \\
$P_{E}$ & $\mathrm{~kW}$ & 13.50 & 13.22 & +2.1 \\
$\mathrm{PF}$ & - & 0.90 & 0.89 & +1.1 \\
\hline
\end{tabular}

$\overline{{ }^{1} \text { Flux density during no-load operation measured in the center of pole body. }{ }^{2} \text { FEA result obtained by multiplying }}$ the rms values of the current, line voltage, and $\sqrt{3} .{ }^{3}$ FEA result obtained by the mean value of the instantaneous power. ${ }^{4}$ Calculated as $P_{E} / S_{E}$. 
Figure 12 shows the phase-to-neutral no-load voltages. The shape of these voltages are typical of this kind of generator, being almost trapezoidal. The inflection points (e.g., $75^{\circ}$ ) are due to a slot opening that reduces the air-gap flux under its area. The THD of this curve is $7 \%$.

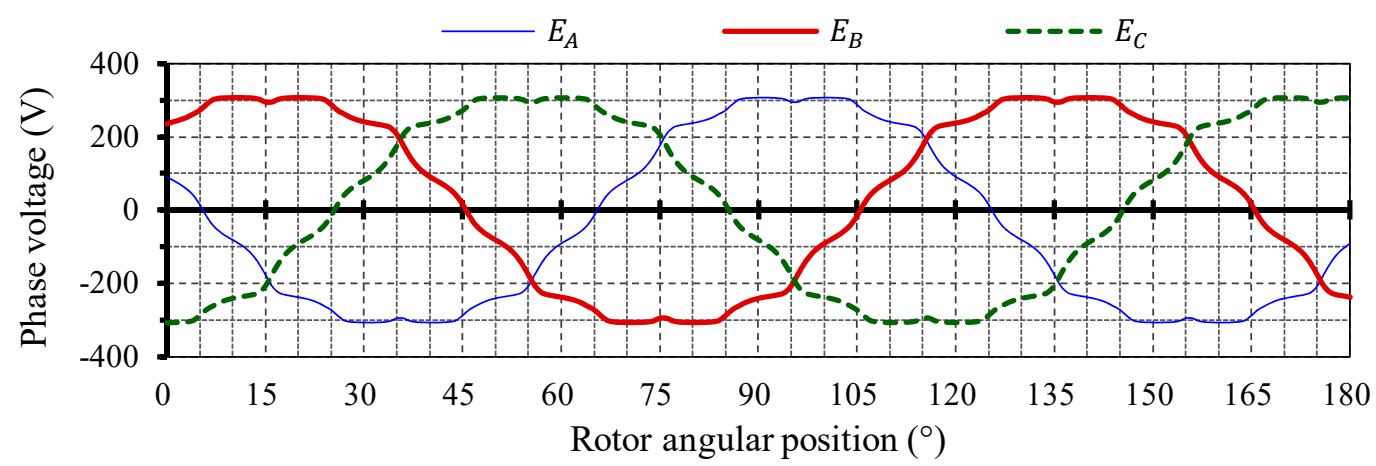

Figure 12. No-load phase voltages (field current equal to $I_{F n l}$ ).

The phase-to-phase voltages under full-load operation and the components of the voltage in the quadrature and direct axis are shown in Figure 13. The variables $V_{q}$ and $V_{d}$ are the quadrature and direct axis components of the voltage obtained from phase voltages by Park's reference frame transformation [22]. The flux distortion caused by armature reaction generally contributes to reducing the harmonic content of the voltage. The THD of the line voltages presented in Figure 13 is $3 \%$, whereby the eleventh-(1.2\%) and the thirteenth-( $2.5 \%)$ order components are the most important.

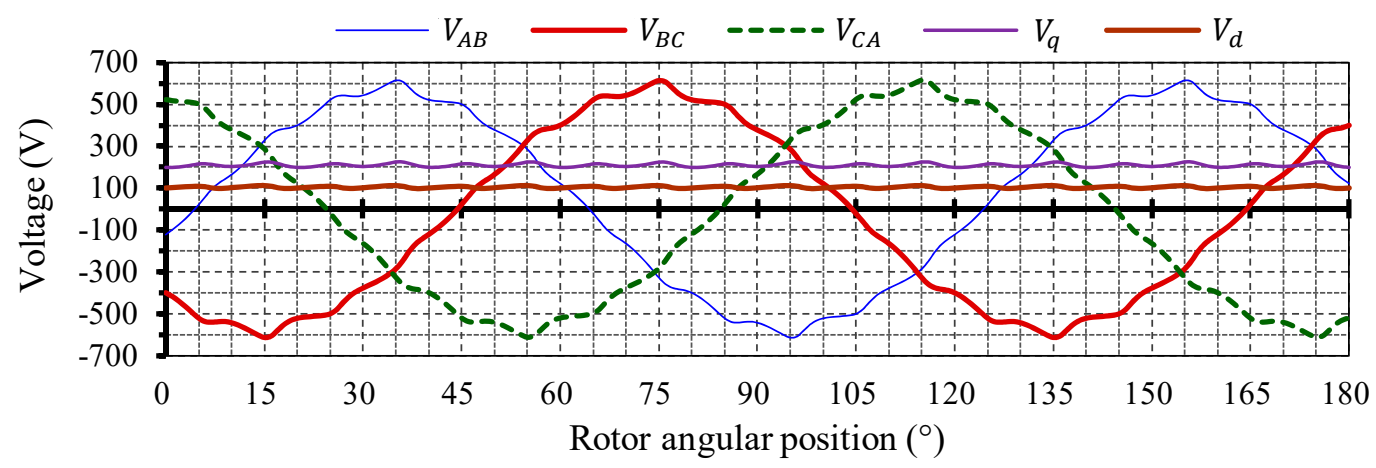

Figure 13. Full-load line voltages and the components of quadrature and direct-axis voltages.

Figure 14 shows the armature currents and the components corresponding to quadrature and direct axis. The THD of armature currents is $9 \%$, where the most important is the third-order component, with $8.4 \%$.

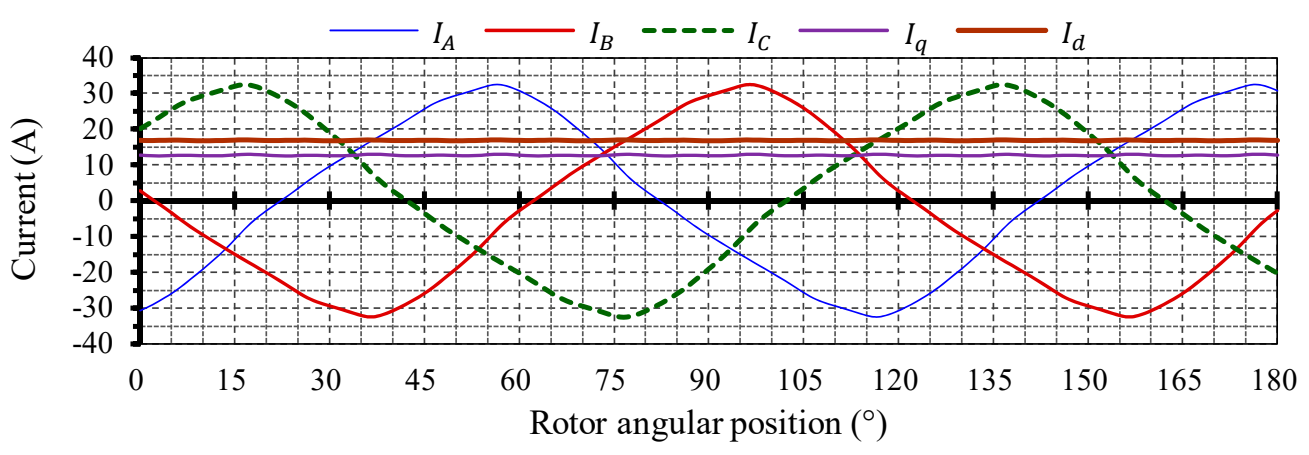

Figure 14. Full-load armature currents and the components of quadrature and direct-axis currents. 
The electromagnetic torque, the three-phase output power (instantaneous power), and its average value are shown in Figure 15. The average value of the electromagnetic torque is $131.6 \mathrm{~N} \cdot \mathrm{m}$, and the average value of the instantaneous power is $13.22 \mathrm{~kW}$, as presented in Table 6 . The ratio between the maximum oscillation and the average value is 0.24 for the electromagnetic torque and 0.14 for the output power. Such oscillations are undesirable and mainly exist due to harmonic content in voltage and current.

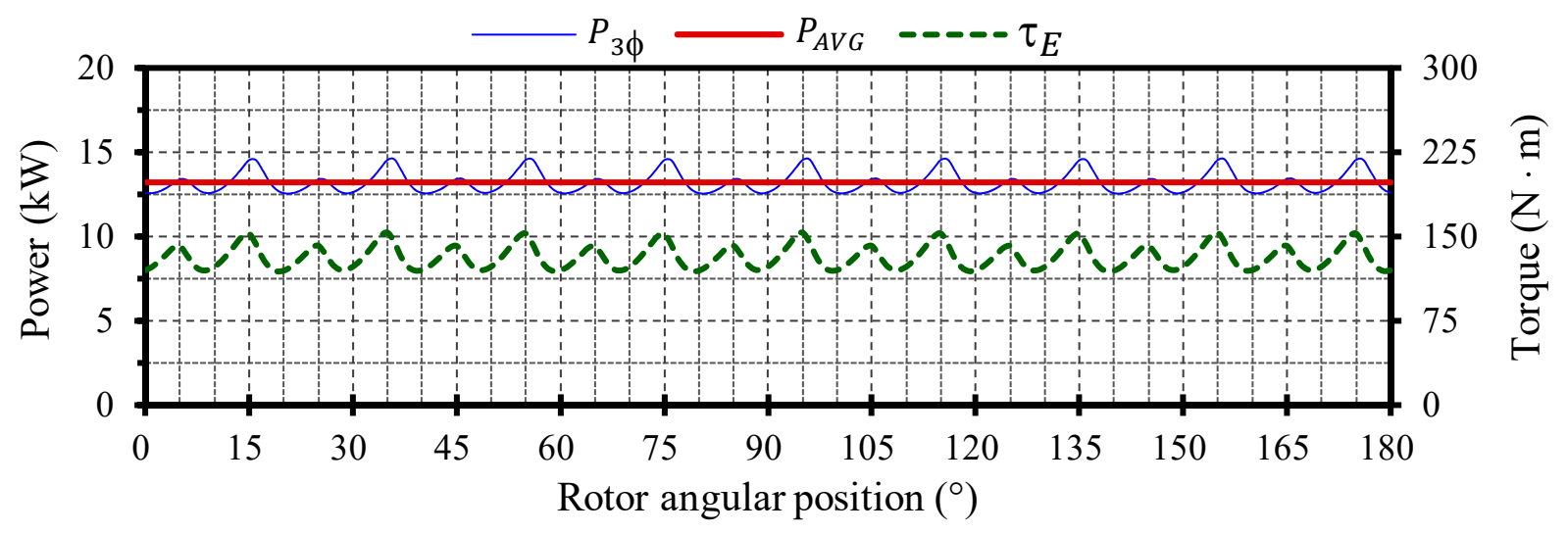

Figure 15. Output power and electromagnetic torque under full-load operation.

\section{Discussions about Improvements in the Design}

The main objective of the proposed method is to provide a simple step-by-step procedure to design small size synchronous generators. The results obtained by such a design could be useful for several purposes, e.g., to provide an application for researches in the areas related to control, optimization, and power electronics. However, the design procedure can be improved in several manners to produce, as a result, a more reliable generator.

The first suggestion of improvement regards harmonic content mitigation. There are three classic techniques to address harmonic reduction: carefully choosing the armature winding configuration, changing the shape of pole shoes, and skewing the stator in relation to the rotor.

Equations (26) and (28) represent the reduction of the linked flux by the armature coil due to, respectively, coil shortening and winding distribution. The coil is shortened if the coil pitch is smaller than the pole pitch and is distributed when there is more than one coil per pole for each phase. In the presented example, the coil is shortened by a factor of 5/6, and the number of coils per pole and phase is two. It is possible to calculate the attenuation factor for each harmonic due to winding distribution by [1]:

$$
\mathrm{K}_{d v}=\frac{\sin \left(v \cdot \frac{q \cdot \alpha_{u}}{2}\right)}{q \cdot \sin \left(v \cdot \frac{\alpha_{u}}{2}\right)}
$$

where $v$ represents the harmonic order, $q$ is the number of slots per pole, and $\alpha_{u}$ is the angle (electrical) between two adjacent coils of the same group.

The attenuation factor due to coil shortening can be obtained by [1]:

$$
\mathrm{K}_{s v}=\sin \left(K_{A c} \cdot v \cdot \frac{\pi}{2}\right)
$$

where $K_{A c}$ is the coil-shortening factor.

Applying (79) and (80) can show how the choices concerning the winding configuration can reduce the harmonic. A shortening factor of $5 / 6$ reduces a significant amount of fifth- and seventh-order components and a moderate amount of third- and ninth-order components, whereas a factor of $2 / 3$ drastically reduces third-and ninth-order components, and moderately, fifth- and seventh-order components. Generally, increasing $q$ provides 
an overall reduction of the harmonic contents, and a fractional $q$ (chosen carefully) can improve the reduction [1].

Another suggestion to reduce harmonics is to change the shape of pole shoes. The presented example has the air-gap constant along the pole shoe's surface. Such a shape produces a trapezoidal flux density in the air-gap [2], contributing to producing harmonic content. The pole shoes can be shaped in order to produce a sinusoidal flux density in the air-gap by making the air-gap larger toward the pole shoe ends, [2] which suggests using:

$$
\mathrm{L}_{A G}(\theta)=\frac{L_{A G}}{\cos \left(\theta \cdot \frac{P}{2}\right)},
$$

where $L_{A G}$ is the air-gap length in the center of pole shoe, $\theta$ is the mechanical angle where $\mathrm{L}_{A G}(\theta)$ is calculated, and $P$ is the number of poles.

A generator with pole shoes shaped as (81) presents a very important attenuation of the harmonic content. An easy way to include it in the design procedure is to replace step 11 by an equivalent reluctance formed by several (10-20 are enough) parallel air-gap reluctances, each one approximated by a rectangle with the same width and different lengths, which can be obtained directly by (81).

Finally, it is possible to skew the stator to reduce the influences of permeance harmonics caused by slots [1]. The reduction factor of each harmonic order due to stator skewing is:

$$
\mathrm{K}_{s q v}=\frac{\sin \left(v \cdot \frac{s}{\tau_{P}} \cdot \frac{\pi}{2}\right)}{v \cdot \frac{s}{\tau_{P}} \cdot \frac{\pi}{2}}
$$

where $s$ is the skewing arc length $(\mathrm{mm})$ and $\tau_{P}$ is the pole pitch arc length obtained in step 74 .

These three suggestions can drastically reduce the current and voltage harmonic contents of the generator, but unfortunately, they also reduce the fundamental component (when $v=1$ ). To compensate such a drawback, it is advised to increase the stack length or the armature number of turns per coil; both solutions increase the generator volume, mass, and material costs.

Another suggestion of improvement is to estimate the operating temperature of the generator. A practical way to estimate the temperature is to implement an equivalent thermal circuit, which models the thermal resistances by resistors, the heating sources (losses) by current sources, and the voltage at each node represents the temperature of the corresponding region. An equivalent thermal circuit of a permanent magnet synchronous generator has been implemented by [5], where the rotor losses have been neglected without spoiling the results. Some guidelines to create an equivalent thermal circuit for electric machines are provided by [3]. More complex and accurate thermal models based on lumped parameters are presented in $[23,24]$.

If the temperature is estimated, the design can benefit from it by using the actual temperature of armature and field windings in steps 40 and 43 . Therefore, the imposition of current density $\left(J_{A}\right.$ and $\left.J_{F}\right)$ are no longer mandatory, and the temperature (if estimated appropriately) may govern the amount of current that the conductors can support.

\section{Conclusions}

A step-by-step procedure to design synchronous generators has been presented. Different from most papers, all equations and methods required to achieve the result are shown, which makes the procedure easy to replicate. Therefore, many researchers can benefit from this procedure to perform a preliminary design of a synchronous generator or to improve it by incorporating other features.

In spite of the simplifications applied in the design, e.g., disregarding the iron reluctance, its results are very close to those obtained with finite-element simulation, where the core reluctance and its saturation have been taken into account. If it is important to consider the iron magnetic permeability, the core reluctances should be calculated based 
on geometry and used to estimate the flux created by field winding. Similarly, the thermal behavior could be implemented, and the shape of pole shoes could be improved to achieve better designs.

The proposed procedure has been applied to an example to help readers to understand how it can be implemented. After the analysis of the results obtained from the example, some considerations and guidelines to improve the design are presented. Such improvements include design choices to reduce harmonics a suggestion to implement an equivalent thermal circuit. However, the paper does not cover a method to create a thermal model or the analytical calculation of the quadrature and direct-axis reactances. Fortunately, the designer interested in refinement of the generator can apply the proposed method to obtain a preliminary design and enhance the results with specialized bibliography.

Author Contributions: Conceptualization, T.d.P.M.B.; Data curation, R.C.; Formal analysis, R.C.; Funding acquisition, T.d.P.M.B.; Investigation, T.d.P.M.B.; Methodology, T.d.P.M.B.; Project administration, T.d.P.M.B.; Resources, T.d.P.M.B.; Software, T.d.P.M.B. and V.d.O.M.; Supervision, T.d.P.M.B.; Validation, T.d.P.M.B., V.d.O.M. and R.C.; Visualization, T.d.P.M.B.; Writing-Original draft, T.d.P.M.B. and V.d.O.M.; Writing-Review and editing, T.d.P.M.B. and R.C. All authors have read and agreed to the published version of the manuscript.

Funding: The APC was funded by Universidade Tenológica Federal do Paraná (UTFPR).

Conflicts of Interest: The authors declare no conflict of interest. The funders had no role in the design of the study; in the collection, analyses, or interpretation of data; in the writing of the manuscript, or in the decision to publish the results.

\section{References}

1. Pyrhönen, J.; Jokinen, T.; Hrabovcova, V. Design of Rotating Electrical Machines, 1st ed.; John Wiley \& Sons: Chichester, UK, 2008.

2. Boldea, I. Synchronous Generators, 2nd ed.; CRC Press: Boca Raton, FL, USA, 2016.

3. Hendershot, J.R.; Miller, T.J.E. Design of Brushless Permanent-Magnet Machines, 1st ed.; Motor Design Books: Venice, CA, USA, 2010.

4. Hanselman, D.C. Brushless Permanent Magnet Motor Design, 2nd ed.; The Writers' Collective: Cranston, RI, USA, 2003.

5. Bazzo, T.P.M.; Kölzer, J.F.; Carlson, R.; Wurtz, F.; Gerbaud, L. Multiphysics Design Optimization of a Permanent Magnet Synchronous Generator. IEEE Trans. Ind. Electron. 2017, 64, 9815-9823. [CrossRef]

6. Bernard, N.; Missoum, R.; Dang, L.; Bekka, N.; Ahmed, H.B.; Zaïm, M.E. Design Methodology for High-Speed Permanent Magnet Synchronous Machines. IEEE Trans. Energy Convers. 2016, 31, 477-485. [CrossRef]

7. Bianchi, N.; Bolognani, S.; Pre, M.D.; Bekka, N.; Grezzani, G. Design considerations for fractional-slot winding configurations of synchronous machines. IEEE Trans. Ind. Appl. 2006, 42, 997-1006. [CrossRef]

8. Laldin, O.; Sudhoff, S.D.; Pekarek, S. An Analytical Design Model for Wound Rotor Synchronous Machines. IEEE Trans. Energy Convers. 2015, 30, 1299-1309. [CrossRef]

9. Nardo, M.D.; Calzo, G.L.; Galea, M.; Gerada, C. Design Optimization of a High-Speed Synchronous Reluctance Machine. IEEE Trans. Ind. Appl. 2018, 54, 233-243. [CrossRef]

10. Yang, C.; Lin, H.; Guo, J.; Zhu, Z.Q. Design and Analysis of a Novel Hybrid Excitation Synchronous Machine with Asymmetrically Stagger Permanent Magnet. IEEE Trans. Magn. 2008, 44, 4353-4356. [CrossRef]

11. Daghigh, A.; Javadi, H.; Torkaman, H. Optimal Design of Coreless Axial Flux Permanent Magnet Synchronous Generator with Reduced Cost Considering Improved PM Leakage Flux Model. Electr. Power Compon. Syst. 2017, 45, 264-278. [CrossRef]

12. Kim, H.; Jeong, J.; Yoon, M.; Moon, J.; Hong, J. Simple Size Determination of Permanent-Magnet Synchronous Machines. IEEE Trans. Ind. Electron. 2017, 64, 7972-7983. [CrossRef]

13. Hebala, A.; Ghoneim, W.A.M.; Ashour, H.A. Detailed Design Procedures for PMSG Direct-Driven by Wind Turbines. J. Electr. Eng. Technol. 2019, 14, 251-263. [CrossRef]

14. Vaschetto, S.; Tenconi, A.; Bramerdorfer, G. Sizing procedure of surface mounted PM machines for fast analytical evaluations. In Proceedings of the IEEE International Electric Machines and Drives Conference (IEMDC), Miami, FL, USA, 21-24 May 2017; IEEE: Piscataway, NJ, USA, 2017. [CrossRef]

15. Uzhegov, N.; Kurvinen, E.; Nerg, J.; Pyrhönen, J.; Sopanen, J.T.; Shirinskii, S. Multidisciplinary Design Process of a 6-Slot 2-Pole High-Speed Permanent-Magnet Synchronous Machine. IEEE Trans. Ind. Electron. 2016, 63, 784-795. [CrossRef]

16. Xiao, Y.; Zhou, L.; Wang, J.; Yang, R. Finite Element Computation of Transient Parameters of a Salient-Pole Synchronous Machine. Energies 2017, 10, 1015. [CrossRef]

17. Jones, C.V. The Unified Theory of Electrical Machines, 1st ed.; Butterworths: London, UK, 1967.

18. Shima, K.; Ide, K.; Takahashi, M. Finite-element calculation of leakage inductances of a saturated salient-pole synchronous machine with damper circuits. IEEE Trans. Energy Convers. 2002, 17, 463-470. [CrossRef] 
19. Misir, O.; Raziee, S.M.; Ponick, B. Determination of the Inductances of Salient Pole Synchronous Machines Based on the Voltage Equation of a Single Coil in the Stator Winding. IEEE Trans. Ind. Appl. 2016, 52, 3792-3804. [CrossRef]

20. Tessarolo, A. Accurate Computation of Multiphase Synchronous Machine Inductances Based on Winding Function Theory. IEEE Trans. Energy Convers. 2012, 27, 895-904. [CrossRef]

21. Grauers, A. Design of Direct-Driven Permanent-Magnet Generators for Wind Turbines, in School of Electrical and Computer Engineering; Chalmers University of Technology: Göteborg, Sweden, 1996.

22. Krause, P.C.; Wasynczuk, O.; Sudhoff, S. Analysis of Electric Machinery and Drive Systems, 2nd ed.; IEEE Press Power Engineering Series: Danvers, MA, USA, 2002.

23. Wang, Y.; Nuzzo, S.; Gerada, C.; Zhao, W.; Zhang, H.; Galea, M. 3D Lumped Parameter Thermal Network for Wound-Field Synchronous Generators. In Proceedings of the IEEE Workshop on Electrical Machines Design, Control and Diagnosis (WEMDCD), Modena, Italy, 8-9 April 2021; IEEE: Piscataway, NJ, USA, 2021. [CrossRef]

24. Ghahfarokhi, P.S.; Kallaste, A.; Podgornov, A.; Belahcen, A.; Vaimann, T.; Kudrjavtsev, O. Thermal Analysis of Salient Pole Synchronous Machines by Multiple Model Planes Approach. In Proceedings of the International Conference on Electrical Machines (ICEM), Gothenburg, Sweden, 23-26 August 2020; IEEE: Piscataway, NJ, USA, 2020. [CrossRef] 